\title{
The Relationship between Self-Leadership, Personality and Job Satisfaction: A Review
}

\author{
Choi Sang Long ${ }^{1}$, Mohd Norfian Alifiah ${ }^{1}$, Tan Owee Kowang ${ }^{1} \&$ Chan Wei Ching ${ }^{2}$ \\ ${ }^{1}$ Faculty of Management, Universiti Teknologi Malaysia, Malaysia \\ ${ }^{2}$ International Business School, Universiti Teknologi Malaysia, Malaysia \\ Correspondence: Choi Sang Long, Faculty of Management, Universiti Teknologi Malaysia, 81310 Johor Bahru, \\ Johor, Malaysia. E-mail: cslong_1@yahoo.com
}

Received: October 23, 2014 Accepted: November 20, 2014 Online Published: January 22, 2015

doi:10.5539/jsd.v8n1p16 URL: http://dx.doi.org/10.5539/jsd.v8n1p16

\begin{abstract}
This review paper explores the relationship between self-leadership, personality and job satisfaction among employees. Self-leadership is define as a set of self-influence strategies that have effective potential for application in various types of organization. Personality is commonly associated with individual's unique behavioral traits. Authors also discuss the Big Five Model Theory and Type A and Type B personality theory. The impacts of the constructs of the two theories on employees' job satisfaction are reviewed in this paper.
\end{abstract}

Keywords: self-leadership, personality, job satisfaction, employees, leadership

\section{Introduction}

According to Rigotti et al. (2008), employees with high occupational self-efficacy can successfully perform their job tasks. Employees who are the one who actually perform the job should be involved in making decisions which are directly related to them and their job. Furthermore, greater equality may inspire behavioral commitment from team members (Corrigall-Brown \& Wilkes, 2012; Hyman \& Mason, 1995).

The $21^{\text {st }}$ century is full with intense competition. Hence, highly competitive labor market can provide organization with a lot of talented workers and can create a condusive working environment for people who really interested to work (Barbuto \& Scholl, 1999). Personality is important to shape our behavior in life, even through in our working life. Therefore, if we really want to know the behavior of a person to satisfy the needs of an organization, we need to know about their personality. According to Bedeian, et al. (1992), perceptions of an individual about politics in their workplace negatively influence their jobs, feelings toward their colleagues, productivity and intention of leaving.

Ali (2009) also commented that high turnover bring destruction to the organization in the form of both direct and indirect cost. According to Abbasi and Hollman (2000), employees who are most likely to leave the organization are those who are most talented and smartest within the group. Their valuable experiences, talent, skills and knowledge will go with them and resulted in deteriorating efficiency.

Many past researches have clearly identified that there are relationship between self- leadership and personality and job satisfaction of employee in their workplace (Salahudin et al., 2009; Gwavuya, 2011; Tasso et al., 2002; Ali, 2009; Park \& Kim, 2009).

\section{Literature Review}

Self-leadership is define as a set of self-influence strategies that have effective potential for application in various types of organization (Jeffery, et al. (2004). Hence, Ebben (2012) concluded that self- leadership strategies are indeed distinct from, yet related to certain personality traits. Self-leadership also can lead to effective leadership, stability and enhanced productivity in organizational context. People or individuals used self-leadership strategies to enhance their personality effectiveness through natural reward, behavior-focused and constructive thought strategies (Manz \& Neck, 2004). Hence, Panja, et al. (2012) summarize that self-leadership is a normative concept that will provides certain behavioral and cognition prescription while operating within and through the theoretical contexts provided by self-regulation, social cognitive, self-control, and intrinsic motivation theories. Therefore, social cognitive career theory is the theory related to self-leadership. 


\subsection{Cognitive and Behavioral Strategies}

For this research, cognitive and behavioral strategies include and relate with behavior-focused strategies, natural reward strategies and constructive thought pattern strategies.

a) Behavior -focused strategies

Manz and Neck (2004) found that behavior-focused strategies are intended to increase self-awareness leading to the management of behaviors involving necessary but perhaps unpleasant tasks. Behavior-focused self-leadership strategies are designed to encourage positive, desirable behaviors that lead to successful outcomes while suppressing negative, undesirable behaviors that will lead to unsuccessful outcomes (Cox et al., 2003). These strategies include self-observation, self-goal-setting, self-motivation and self-explorer. According to Manz (1992) and Manz and Neck (1999), a behavior-focused strategy is to enhance the self-conscientious; increase an individual or people self-conscientious in order to the management of necessary, occasionally unlikable and behaviors.

b) Natural reward strategies

According to Sharon (2008), natural reward strategies helps individuals shape perceptions and build enjoyable aspects into activities they involved. Manz (1986) found that natural reward strategies focus on the inherently enjoyable aspects of a given task or activity that will create feelings of competence, self-control, and purpose by enhancing intrinsic motivation. Besides, natural reward strategies have two primary reward strategies; first is to enjoy the task that enable someone to facilitate optimal functioning and the task itself becomes naturally rewarding. The second strategy is to refocus in the task's inherently rewarding aspects and shaping the perception by focusing attention away from the undesirable facet of the assignment (Manz \& Neck, 2004). Lastly, Thomas (2000) mention that doing "the right things" will make people feel good and happy.

c) Constructive thought pattern strategies

Constructive thought pattern strategies deal with the creation or alternation of cognitive thought processes. According to Manz and Neck (2004), these strategies enable individuals to identify dysfunctional beliefs and create new thought patterns of changing existing thoughts into more positive one. These strategies facilitate the generation of habitual ways of thinking that positively influence performance. Constructive thought pattern strategies are often referred to as thought self-leadership. It suggests that individuals can influence and control their own thoughts through the use of specific cognitive strategies designed to facilitate the formation of constructive thought patterns that can positively affect performance (Neck \& Manz, 1992). In addition, constructive thought pattern strategies may be particularly useful in increasing team members' self-efficacy beliefs for sharing leadership roles. For example, team member may be suffering from dysfunctional beliefs and assumptions and from negative self-talk relative to his ability to engage in leadership behaviors (Cox et al., 2003).

\subsection{Personality Theory}

Personality theory was an important element of the counseling relationship that explore different culture to improve people ability to engage in effective relationships with others (Russel et al., 2002). Personality is an individual's unique constellation of consistent behavioral traits. In this research, Big Five Model and Type A and Type B personality theory has been chosen.

\section{a) Big Five Model}

The Big Five model is a hierarchical organization of personality traits in terms of five basic dimensions that include openness to experience, conscientiousness, extroversion, agreeableness and neuroticism or called emotional stability (McCrae \& Oliver, 1992). The Big Five factors are shown in Table 1: 
Table 1. Big five model

\begin{tabular}{lll}
\hline \multicolumn{1}{c}{ Traits } & \multicolumn{1}{c}{ Description } \\
\hline $\mathrm{O}$ & Openness to experience & $*$ Being curious, original, intellectual, creative and open new ideas \\
$\mathrm{C}$ & Conscientiousness & $*$ Being organized, systematic, punctual, achievement oriented and \\
& & dependable. \\
$\mathrm{E}$ & Extroversion & $*$ Being outgoing, talkative, sociable and enjoying social situations \\
$\mathrm{A}$ & Agreeableness & $*$ Being affable, tolerant, sensitive, trusting, kind and warm. \\
$\mathrm{N}$ & Neuroticism or Emotional & $*$ Being anxious, temperamental and moody \\
& stability &
\end{tabular}

\section{Extroversion}

Extroversion is marked by pronounced engagement with the external world. Therefore, extroverts can be divided into two types that are extroverts and introverts. Extroverts can get their energy from interacting with others; they like to communicate with people, full of energy, often create positive emotions and is the people who like to say " Yes" or "Let's go" to opportunities for excitement. Introverts will be the opposite meaning from extroverts. They will get their energy from within themselves, lack of energy, do not take part in activity and do not socialize (Costa \& McRae, 1992). Lastly, extroversion shows energy, positive emotions, and the tendency to seek stimulation in the company of others.

\section{Agreeableness}

Agreeableness was a tendency to be compassionate cooperative rather than suspicious and antagonistic towards others. According to Bligh (2011), agreeableness or an individual's tendency to be able to trust, conforming and accepting, has weak relationship with leadership. Therefore, agreeableness bring advantages for attaining and maintaining popularity and it will reflects people or individual differences concerning with cooperation and social harmony. High agreeableness describes a person who will react to others with warmth and will bend to avoid conflict. While low agreeableness described as only following one's inner voice regardless of others' feelings (Costa \& McRae, 1992). Hence, agreeable people will normally be helpful, friendly and cooperative. Agreeableness includes traits like kind, sympathetic and warm.

\section{Openness to experience}

Openness to experience includes the attitude or appreciation for art, emotion, adventure, unusual ideas, curiosity and variety of experience. Openness to experience also means people who like to learn new things and always enjoy their new experiences. High openness refers to the person with relatively more interests, consequently and relatively less depth within each interest. A person with low openness will have relatively few interests and relatively more depth in each of those interests (Costa \& McRae, 1992). Therefore, openness to experience includes traits like being imaginative and having a wide variety of interests.

\section{Conscientiousness}

Conscientiousness refers to goal-directed behavior and a tendency to show self- discipline, act dutifully, aim for achievement and will plan rather than having spontaneous behavior. People who have conscientiousness are reliable and prompt. High conscientiousness refers to a person who focuses intensely on his or her goals and exhibits the self-discipline associated with such focus. Therefore, low conscientiousness refers to one who is disorganized and distracted (Costa \& McRae, 1992). Lastly, conscientiousness is defined as an individual's tendency to be organized, through, controlled, decisive and dependable (Bligh, 2011).

\section{Emotional stability or Neuroticism}

Emotional stability is also called neuroticism. It is related with emotional stability, degree of negative emotions and anxiety. Emotional stability has been moderately and negatively related to leadership, and previous study suggested that most leaders tend to be low in neuroticism (Bligh, 2011). Emotional stability experience unpleasant emotions easily, like anger, anxiety and depression. According to Costa and McRae (1992), more resilient people (high on emotional stability) are less prone to experiencing negative reactions. Therefore, emotional stability included traits like moody and tense. 


\section{b) Type A Personality}

Type A is one of the personality theories and it generally refers to hard workers who are often preoccupied with schedules and the speed of their performance. The tendency of being self-critical is high among Type A individuals. Type A behavior always includes competitiveness and strong achievement-orientation. Type A personality characteristics are more of a reaction to environmental factors or tendencies toward certain behaviors. For example:

$>$ Many jobs put heavy demands on time, making it necessary for workers to be very concerned with getting things done quickly if they're to adequately get their job done.

$>$ Some workplace put heavy penalties on mistakes, so efficiency and achievement becomes extremely important.

Other jobs just create more stress, making people less patient, more stressed, and more prone to "Type A" behaviors.

c) Type B Personality

Type B personality is exactly different or opposite of Type A. Type A personalities may be more creative, imaginative and philosophical than Type B personalities. Therefore, Type B personality generally lives at a lower stress level and are typically work steadily, enjoying achievements but not becoming stressed and enjoy exploring ideas and concept. Stress can be dealt much easier for Type B personality. These individuals do not suffer from anxiety, and hence have lower the risk of suffering from ailment such as heart disease. Lastly, Type B personality prevails in individuals who are calm and have an easy-going attitude and they are fun-loving and relatively less competitive.

\subsection{Relationship between Self-Leadership and Job Satisfaction}

Javadi, et al. (2013), has tested the relationship between self-leadership strategies and job satisfaction at an educational organization in Isfahan. 180 employees were selected but only 164 employees completed the questionnaire. This study had showed that the behavior focused strategies, natural reward strategies and constructive thought pattern strategies had a significant effect on job satisfaction and self-leadership. The findings showed that self-leadership can be considered as a predictor of job satisfaction. Besides that, the results also stated that having self-leadership characteristic can influence on enhancing job satisfaction. So, training the self-leadership skills for employees is a good way to increase their job satisfaction (Javadi et al., 2013).

John (2005) has investigated the relationship of self-leadership behavioral-focused strategies and job satisfaction. The questionnaires were completed by 304 employees from a manufacturing organization in Australia. This study was conducted to examine whether organizations should develop and deliver training programs to allow their employees to apply self-leadership strategies at work and to improve employees' job satisfaction, confidence and performance outcomes. The results suggested that organizations must create more complex empowerment interventions and job satisfaction mediates the relationship between self-leadership behavioral-focused strategies and team performance (John, 2005).

Heather and Roseanne (1989) conducted a study to evaluate the interaction of self-leadership and work structure in predicting job satisfaction. A total of 76 employees from two divisions of a large manufacturing firm in mid-Atlantic region were chosen in this research. The survey found that satisfaction was higher for employees with high self-leadership. However, satisfaction was higher for employees with low self-leadership who worked in high structure environments. (Heather \& Roseanne, 1989).

In addition, Ali Mohammad and Mohammad Hossein (2006) found that there is a relationship between leadership type and job satisfaction. 814 employees from the first line, middle line and senior managers of hospitals in Iran were chosen in this research. The sample was chosen based on a stratified random sampling. According this research, employees demonstrated less satisfaction with salary, benefit, promotion and communication and more satisfaction with factors like nature of the job, workers and supervision type factors. These results suggested that employee job satisfaction normally depends upon leadership style of management.

\subsection{Relationship between Personality and Job Satisfaction}

Adrian, et al. (2002) examined the relationship between personality traits and aspects of job satisfaction. 30 male and 52 female full time employees from three different companies in positions ranging from administration to senior management took part in this study. The researchers concluded that personality traits does not have a strong or consistent influence either on what individuals perceive as important in their job environment or on their level of job satisfaction (Adrian, et al., 2002) . 
Rothmann and Coetzer (2002) had investigated on the relationship between personality dimensions (Big Five Model) and job satisfaction in a pharmaceutical organization in South Africa. The samples were collected from 159 employees in a pharmaceutical organization and Minnesota Satisfaction Questionnaire and NEO Personality Inventory Revised were used as measuring instruments. They found that job satisfaction has a negative relationship with neuroticism, and it has a positive relationship with extroversion and agreeableness; as well as facets of conscientiousness.

Selin and Pinar (2011) had also studied on the relationship between personality traits (conscientiousness, extroversion, agreeableness and neuroticism) and job satisfaction in insurance companies. Survey data were collected from 218 employees. They found that organizations should focus more on developing employees' justice which is the underlying relationship between personality and job satisfaction. Besides, this study also demonstrated that the relationship between conscientiousness and job satisfaction were completely mediated by procedural justice, therefore the relationship between extroversion, agreeableness and neuroticism and job satisfaction were partially mediated by procedural justice (Selin \& Pinar, 2011).

Sampath (2012) conducted a study to investigate the impact of the Five factor model of personality on job satisfaction of non-academic employees' in Sri Lankan universities. The data was tested using correlation coefficient and regression analysis. A total 150 non-academic employees from the University of Rajarata, Wayamba and Sabaragamuwa was chosen in this study. From the survey, extroversion, agreeableness and conscientiousness of non-academic employees had significant positive relationships with their job satisfaction. Second, significant negative relationship was reported between neuroticism and job satisfaction. Third, openness to experience had insignificant relationship with job satisfaction. As a conclusion, the five factor model had an important influence on non-academic employees' job satisfaction.

Tesdimir, et al. (2012) has examined the effects of the personality traits and job satisfaction among professional sales representatives working in the pharmaceutical industry in Turkey. 450 sales persons from Turkish pharmaceutical companies were chosen in this study. This study showed that personality traits can be an important factor and make a difference in job satisfaction. For example, manager can utilize the personality traits as a screening in recruiting to select and retain good personal sales representative. Personal sales representative who had an extra or more pharmaceutical experience will have higher job satisfaction. The results showed that personal sales representative who had a higher education level will had lower job satisfaction.

Harold (2010) also found that personality traits in relation to job satisfaction of management educators. The study evaluated Big Five personality traits and general job satisfaction. 175 management faculty members from 25 business schools were chosen in this study. However, this study showed that personality tests is useful in the hiring processes like hiring the right candidates; as job satisfaction, almost leads to higher level of productivity and effectiveness.

Richardson, et al. (2009) had examined the relationship between personality traits (Big Five Model) and job satisfaction. The research proved that business majors scored higher for conscientiousness, emotional stability, extroversion, assertiveness and tough-mindedness but scored lower for agreeableness and openness to experience. Therefore, all personality traits except agreeableness and touch-mindedness correlated significantly and positively with job satisfaction (Richardson et al., 2009).

Lavanda (2013) also demonstrated that there was a significant relationship between personality and job satisfaction amongst workers in Bahamas. The sample was collected from 384 workers in the New Providence. The study found that the internal locus of control is highly correlated with job satisfaction. The results indicated that there is a positive impact from an individual personality on job satisfaction (Lavanda, 2013).

Mi Hwa Jung and Myung Suk Koh (2012) had studied on the effects of preceptor nurses' self-leadership on role recognition and job satisfaction. 171 preceptor nurses who worked in one of the three general hospitals in Seoul were chosen in this study. Role recognition was found to be important but they also found that to improve preceptor's job satisfaction, special training programs should or must be added or provided to enhance all preceptor's self-leadership.

\subsection{Conceptual Framework}

Base on the above literature review, a conceptual framework is developed as shown in Figure 1. It shows the dependent variable (DV) that is job satisfaction and two independent variables (IV) that are self-leadership and personality. These independent variables are found to be associated with the level of job satisfaction among employees. 
(IV)

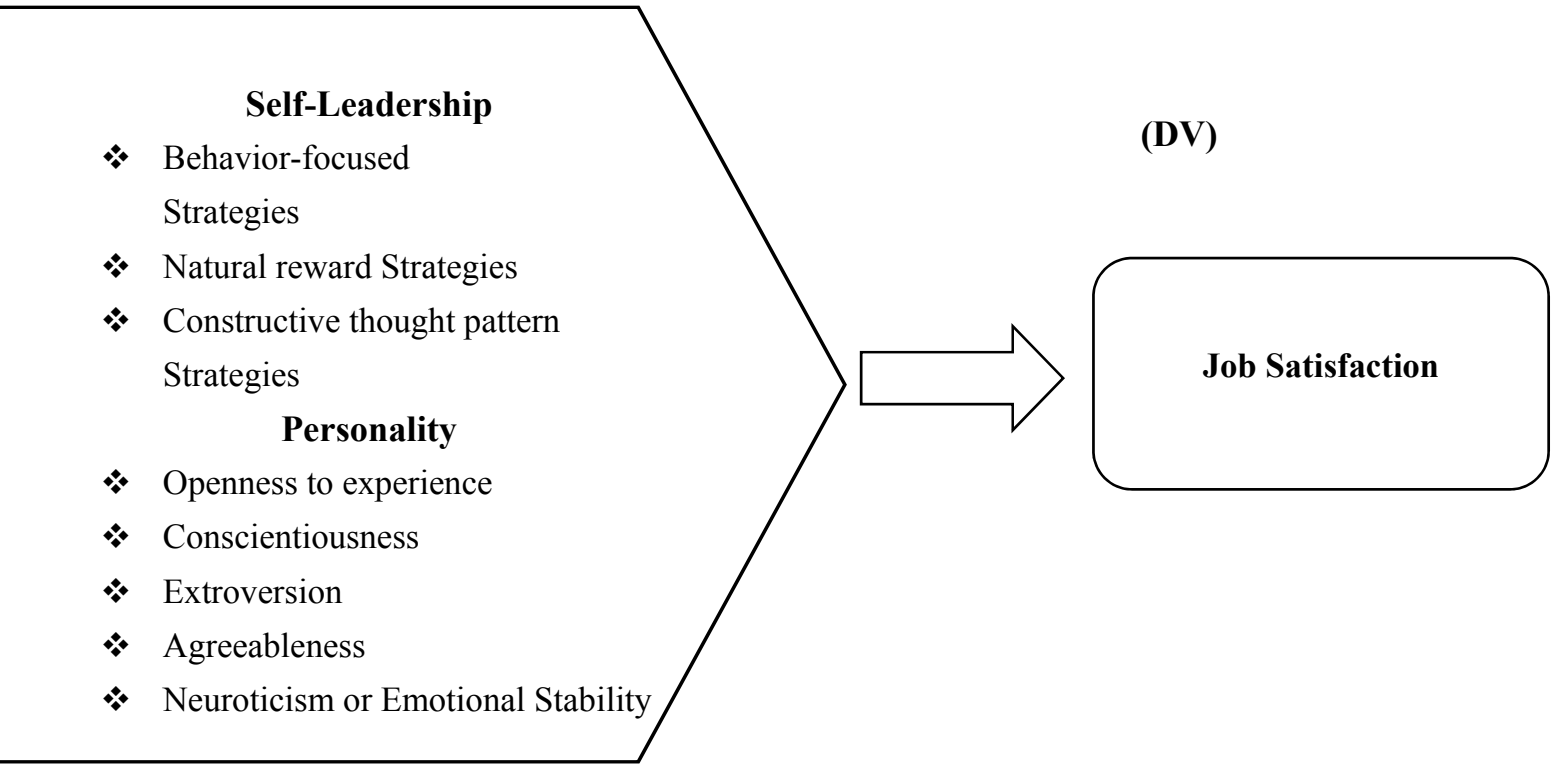

Figure 1. Proposed conceptual framework

\section{Acknowledgement}

Authors wish to acknowledge the Malaysian Ministry of Higher Education and Universiti Teknologi Malaysia under the Research Grant (Vot. 4F349) for supporting this publication.

\section{References}

Abbasi, S., \& Hollman, K. (2000). Turnover: The Real Bottom-line. Public Personnel Management, 29(3), 333-342.

Adrian, F., Petrides, K. V., Chris, J. J., \& Tim, C. (2002). Do personality factors predict job satisfaction? Journal from Personality and Individual Differences, 33, 1325-1342. http://dx.doi.org/10.1016/S0191-8869(02)00016-8

Ali Mohammad, M. R., \& Mohammad Hossein, Y. (2006). A study of relationship between managers' leadership style and employees' job satisfaction. Leadership in Health Services, 19(2), 11-28. http://dx.doi.org/10.1108/13660750610665008

Ali, N. (2009). Factors Affecting Overall Job Satisfaction and Turnover Intention. Journal of Managerial Sciences, 2(2), 239-252.

Barbuto, J., \& Scholl, R. (1999). Leader's motivation and leader's perception of follower's motivation as predictors of leader's influence tactics. Psychological Reports, 84, 1087-1098. http://dx.doi.org/10.2466/pr0.1999.84.3c.1087

Bedeian, A., Ferris, G., \& Kacmar, K. (1992). Age, tenure, and job satisfaction: A tale of two perspectives. Journal of Vocational Behavior, 40, 33-48. http://dx.doi.org/10.1016/0001-8791(92)90045-2

Bligh, M. C. (2011). Personality Theories of Leadership. Encyclopedia of Group Processes and Intergroup Relations, SAGE Publications.

Corrigall-Brown, C., \& Wilkes, R. (2012). Picturing Protest: The Visual Framing of Collective Action by First Nations in Canada. American Behavioral Scientist, 56, 223-243. http://dx.doi.org/10.1177/0002764211419357

Costa, P. T. Jr., \& McRae, R. R. (1992). Revised NEO Personality Inventory (NEO-PI-R) and NEO Five-Factor Inventory (NEO-FFI) professional manual. Odessa, Florida: Psychological Assessment Resources, Inc.

Cox, J. F., Pearce, C. L., \& Perry, M. L. (2003). Toward a model of shared leadership and distributed influence in the innovation process: How shared leadership can enhance new product development, team dynamics and effectiveness. In C. L. Pearce, \& J. A. Conger (Eds.), Shared Leadership: Reframing the hows and whys of 
leadership. Thousand Oaks, CA: Sage. http://dx.doi.org/10.4135/9781452229539.n3

Ebben, V. Z. (2012). The Relationship between Self-leadership and Certain Personality Traits among a Group of First-line Supervisors. Department of Industrial Psychology, University of the Free State, Bloemfontein, South Africa.

Gwavuya, F. (2011). Leadership Influences on Turnover Intentions of Academic Staff in Institutions in Zimbabwe. Academic Leadership Journal, 9(1), 1-15.

Harold, A. P. (2010). Personality traits in relation to Job Satisfaction of Management Educators. Asian Journal of Management Research, 239-249.

Heather, E. R., \& Roseanne, J. F. (1989). Evaluating the Interaction between Self-Leadership and Work Structure in Predicting Job Satisfaction. Journal of Business and Psychological, 12(3), 257-267.

Hyman, J., \& Mason, B. (1995). Managing employee involved and participation. Sage Publications: London.

Javadi, H. S. M., Rezaee, M. S., \& Salehzadeh, R. (2013). Investigating the relationship between self-leadership strategies and job satisfaction. International Journal of Academic Research in Accounting, Finance and Management Sciences, 3, 284-289.

Jeffery, D. H., Bonham, C. P. N., \& Kusum S. (2004). The relationship between self leadership and personality. Journal of Managerial Psychology, 19(4), 427-441. http://dx.doi.org/10.1108/02683940410537963

John, D. P. (2005). Self-Leadership Behavioral-Focused Strategies and Team performance-The mediating influence of Job satisfaction. Leadership and Organization Development Journal, 27(3), 203-216.

Jung, M. H., \& Koh, M. S. (2012). The Effect of Preceptor Nurses's Self-Leadership on Role Recognition and Job satisfaction. Journal of Korean Academy of Nursing Administration, 146-154. http://dx.doi.org/10.11111/jkana.2012.18.2.146

Lavanda, C. (2013). Personality as Predictor of Job Satisfaction: Study of the Relationship between Personality and Job Satisfaction amongst workers in the Bahamas. Journal of Management Research, 5(3), 200-229.

Manz, C. C. (1986). Self-leadership: Toward an expanded theory of self-influence processes in organization. Academy of Management Review, 11, 585-600.

Manz, C. C. (1992). Mastering Self-Leadership: Empowering Yourself for Personal Excellence. Prentice-Hall, Englewood Cliffs, New Jersey.

Manz, C. C., \& Neck, C. P. (1999). Mastering Self-Leadership: Empowering Yourself for Personal Excellence (2nd ed.). Prentice-Hall, Englewood Cliffs, New Jersey.

Manz, C. C., \& Neck, C. P. (2004). Mastering Self-Leadership for Personal excellence (3rd ed.). Prentice Hall, Upper Saddle River, New Jersey.

Manz, C. C., \& Neck, C. P. (2004). Mastering self-leadership: Empowering yourself for personal excellent (3rd edition). Upper Saddle River, New Jersey: Prentice Hall.

McCrae, R. R., \& Oliver, P. J. (1992). An introduction to the five-factor model and its applications. Journal of Personality, 60(2), 175-215. http://dx.doi.org/10.1111/j.1467-6494.1992.tb00970.x

Neck, C. P., \& Manz, C. C. (1992). Thought self-leadership: The impact of self-talk and mental imagery on performance. Journal of Organizational Behavior, 12, 681-699. http://dx.doi.org/10.1002/job.4030130705

Panja, A., Udo, K., \& Christopher, P. N. (2012). The Relation between Self-Relationship and Transformational Leadership: Competing Models and the Moderating Role of Virtuality. Journal of Leadership \& Organizational Studies, 19, 68-80. http://dx.doi.org/10.1177/1548051811425047

Park, J. S., \& Kim, T. H. (2009). Do types of organizational culture matter in nurse job satisfaction and turnover intention? Leadership and Health Service, 22, 20-38. http://dx.doi.org/10.1108/17511870910928001

Richardson, J. R., Lounsbury, J. W., Bhaskar, T., Gibson, L. W., \& Drost, A. W. (2009). Personality traits and career satisfaction of healthcare professionals. Health Care Manager, 28(3), 218-226. http://dx.doi.org/10.1097/HCM.0b013e3181b3e9c7

Rigotti, T., Schyns, B., \& Mohr, G. (2008), A Short Version of the Occupational Selfefficacy Scale: Structural and Construct Validity across Five Countries. Journal of Career Assessment, 16(2), 238-255. http://dx.doi.org/10.1177/1069072707305763

Rothmann, S., \& Coetzer, E. (2002). The relationship between personality dimensions and job satisfaction. 
Business Dynamics, 11(1), 29-42.

Russel, L. T., Daniel, F. B., Alfred, F. C., \& Marie, L. M. (2002). Five-Factor Model (Big Five) Personality Traits and Universal-Diverse Orientation in Counselor Trainees. The Journal of Psychology, 136(5), 561-572. http://dx.doi.org/10.1080/00223980209605551

Salahudin, S. N., Baharin, N. L., Abdullah, M. M., Harun, M. Z. M., \& Taufek, F. H. M. (2009). Occupational content and turnover intention: A case study of small and medium sized enterprises. Proceedings of International Conference on Human Capital Development.

Sampath, K. (2012). The Impact of Five-Factor Model of Personality on Job Satisfaction of Non-academic employees in Sri Lankan Universities. South East Asian Journal of Contemporary Business, Economic and Law, 1, 85-91.

Selin, M. C., \& Pinar, B. K. (2011). Managing Job Satisfaction: The Mediating Effect of Procedural Fairness. International Journal of Business and Social Sciences, 2(8), 234-243.

Sharon, E. N. (2008). An Examination of Self-Leadership. Emerging Leadership Journals, 1(2), 43-61.

Tasso, K., Beha-Horenstein, L. S., Aumille, A., Gamble, K., Grimaudo, N., Guin, P., Mandell, T., \& Ramey, B. (2002). Assessing patient satisfaction and quality of care through observation and interview. Hospital topics: research and perspectives on healthcare, 80, 4-10. http://dx.doi.org/10.1080/00185860209597996

Tesdimir, M. Z., Asghar, M. Z., \& Sana, S. (2012). Study of Relationship of Personality Traits and Job Satisfaction among Professional Sales Representative in Pharmaceutical industry in Turkey. Proceedings of 2nd International Conference on Business Management.

Thomas, K. W. (2000). Intrinsic Motivation at Work: Building Energy and Commitment. San Francisco: Berrett-Koehler.

\section{Copyrights}

Copyright for this article is retained by the author(s), with first publication rights granted to the journal.

This is an open-access article distributed under the terms and conditions of the Creative Commons Attribution license (http://creativecommons.org/licenses/by/3.0/). 